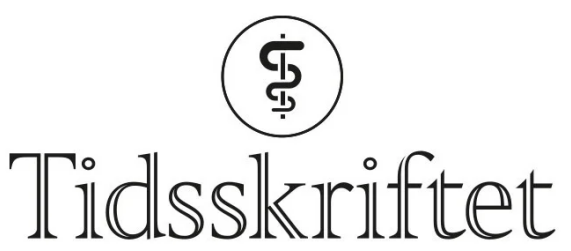

DEN NORSKE LEGEFORENING

\title{
Hjerneovervåking i sykehusene må styrkes
}

KRONIKK

\section{ANNE HEGE AAMODT}

a.h.aamodt@medisin.uio.no

Anne Hege Aamodt er ph.d., spesialist i nevrologi og overlege ved Nevrologisk avdeling ved Oslo universitetssykehus. Hun er nestleder i Norsk hjerneslagforening.

Forfatteren har fylt ut ICMJE-skjemaet og oppgir ingen interessekonflikter.

\section{ERIK TAUBØLL}

Erik Taubøll er dr.med., spesialist i nevrologi, overlege ved Nevrologisk avdeling ved Oslo universitetssykehus og professor ved Universitetet i Oslo.

Forfatteren har fylt ut ICMJE-skjemaet og oppgir ingen interessekonflikter.

\section{TOM EICHELE}

Tom Eichele er ph.d., spesialist i klinisk nevrofysiologi og avdelingssjef i klinisk nevrofysiologi ved Nevroklinikken ved Haukeland universitetssjukehus.

Forfatteren har fylt ut ICMJE-skjemaet og oppgir ingen interessekonflikter.

\section{LUIS ROMUNDSTAD}

Luis Romundstad er dr.med., spesialist i anestesiologi og overlege ved Avdeling for anestesiologi ved Oslo universitetssykehus, Rikshospitalet.

Forfatteren har fylt ut ICMJE-skjemaet og oppgir ingen interessekonflikter.

\section{ANGELIKA SORTEBERG}

Angelika Sorteberg er dr.med., professor i nevrokirurgi ved Institutt for klinisk medisin ved Universitetet i Oslo og overlege ved Nevrokirurgisk avdeling ved Oslo universitetssykehus. Forfatteren har fylt ut ICMJE-skjemaet og oppgir ingen interessekonflikter.

\section{SEAN WALLACE}

Sean Wallace er ph.d. og overlege ved Barneavdeling for nevrofag ved Oslo universitetssykehus. Han er leder i Norsk barnenevrologisk forening. Forfatteren har fylt ut ICMJE-skjemaet og oppgir ingen interessekonflikter.

\section{ANNETTE FROMM}

Annette Fromm er ph.d., spesialist i nevrologi og overlege ved Nevrologisk avdeling ved Haukeland universitetssjukehus. Hun er styremedlem i Norsk hjerneslagforening. Forfatteren har fylt ut ICMJE-skjemaet og oppgir ingen interessekonflikter. 
Marie Furuholmen Raastad er nevrosykepleier og undervisningssykepleier ved Nevrologisk avdeling ved Oslo universitetssykehus. Hun er styremedlem i Norsk Sykepleierforbunds faggruppe for Nevrosykepleiere.

Forfatteren har fylt ut ICMJE-skjemaet og oppgir ingen interessekonflikter.

\section{TROND SAND}

Trond Sand er dr.med., spesialist i klinisk nevrofysiologi og nevrologi, professor ved Institutt for nevromedisin og bevegelsesvitenskap ved NTNU og seksjonsoverlege ved Klinisk nevrofysiologisk laboratorium, Avdeling for nevrologi og klinisk nevrofysiologi, Nevroklinikken, St. Olavs hospital. Forfatteren har fylt ut ICMJE-skjemaet og oppgir ingen interessekonflikter.

\section{KAROLINA SKAGEN}

Karolina Skagen er ph.d., spesialist i nevrologi og overlege ved Nevrologisk avdeling ved Oslo universitetssykehus.

Forfatteren har fylt ut ICMJE-skjemaet og oppgir ingen interessekonflikter.

\section{AGNETHE ELTOFT}

Agnethe Eltoft er ph.d., spesialist i nevrologi og overlege ved Nevrologisk seksjon ved Universitetssykehuset Nord-Norge, Tromsø. Hun er styremedlem i Norsk hjerneslagforening. Forfatteren har fylt ut ICMJE-skjemaet og oppgir ingen interessekonflikter.

\section{CHRISTINA KEFALOYKOS}

Christina Kefaloykos er master i klinisk sykepleievitenskap og nevrosykepleier ved Nevrologisk avdeling ved Oslo universitetssykehus.

Forfatteren har fylt ut ICMJE-skjemaet og oppgir ingen interessekonflikter.

\section{SHIRIN K. FRISVOLD}

Shirin K. Frisvold er ph.d., spesialist i anestesiologi, avdelingsoverlege ved Intensivavdelingen ved Universitetssykehuset Nord-Norge, Tromsø, og postdok ved Helse Nord. Forfatteren har fylt ut ICMJE-skjemaet og oppgir ingen interessekonflikter.

\section{KRISTIAN BERNHARD NILSEN}

Kristian Bernhard Nilsen er ph.d., spesialist i klinisk nevrofysiologi og seksjonsleder ved Seksjon for klinisk nevrofysiologi, Nevrologisk avdeling, Oslo universitetssykehus. Forfatteren har fylt ut ICMJE-skjemaet og oppgir ingen interessekonflikter.

\section{MARIA CARLSSON}

Maria Carlsson er spesialist i nevrologi og overlege ved Nevrologisk avdeling ved Nordlandssykehuset, Bodø. Hun er styremedlem i Norsk hjerneslagforening. Forfatteren har fylt ut ICMJE-skjemaet og oppgir ingen interessekonflikter.

\section{GEIR BRÅTHEN}

Geir Bråthen er dr.med., spesialist i nevrologi, klinikksjef ved Nevroklinikken og overlege ved Avdeling for nevrologi og klinisk nevrofysiologi, St. Olavs hospital, og førsteamanuensis ved NTNU. Forfatteren har fylt ut ICMJE-skjemaet og oppgir ingen interessekonflikter.

\section{IDA BAKKE}

Ida Bakke er spesialist i nevrologi og ph.d.-stipendiat ved Seksjon for pasientsikkerhet ved Nordlandssykehuset. Hun er styremedlem i Norsk nevrologisk forening. Forfatteren har fylt ut ICMJE-skjemaet og oppgir ingen interessekonflikter.

\section{MORTEN ANDREAS HORN}

Morten Andreas Horn er ph.d., spesialist i nevrologi og overlege og leder av fagteam for intensivnevrologi ved Nevrologisk avdeling ved Oslo universitetssykehus. 


\section{MARKUS WIEDMANN}

Markus Wiedmann er ph.d., spesialist i nevrologi og overlege ved Nevrokirurgisk avdeling ved Oslo universitetssykehus.

Forfatteren har fylt ut ICMJE-skjemaet og oppgir ingen interessekonflikter.

\section{BJØRN TENNØE}

Bjørn Tennøe er spesialist i radiologi og seksjonsoverlege ved Seksjon for nevroradiologi ved Oslo universitetssykehus, Rikshospitalet.

Forfatteren har fylt ut ICMJE-skjemaet og oppgir ingen interessekonflikter.

\section{JON ANDRÉ TOTLAND}

Jon André Totland er spesialist i radiologi med fagområde nevroradiologi og overlege ved Universitetssykehuset Nord-Norge.

Forfatteren har fylt ut ICMJE-skjemaet og oppgir ingen interessekonflikter.

\section{OLE MORTEN RøNNING}

Ole Morten Rønning er dr.med., seksjonsoverlege ved Seksjon for akutt hjerneslag, Nevroklinikken, Akershus universitetssykehus, og professor ved Universitetet i Oslo. Han er styremedlem i Norsk hjerneslagforening.

Forfatteren har fylt ut ICMJE-skjemaet og oppgir ingen interessekonflikter.

\section{MARTIN KURZ}

Martin Kurz er ph.d., spesialist i nevrologi, seksjonsoverlege ved Nevrosenteret ved Stavanger universitetssykehus og professor II ved Klinisk institutt 1 ved Universitetet i Bergen. Han er leder i Norsk hjerneslagforening.

Forfatteren har fylt ut ICMJE-skjemaet og oppgir ingen interessekonflikter.

\section{ANETTE STORSTEIN}

Anette Storstein er ph.d., spesialist i nevrologi og overlege ved Nevrologisk avdeling ved Haukeland universitetssjukehus.

Forfatteren har fylt ut ICMJE-skjemaet og oppgir ingen interessekonflikter.

\section{God hjerneovervåking redder liv og helse. Likevel mangler Norge retningslinjer for hjerneovervåking i sykehus.}

Det er i dag stor variasjon i hvor godt hjernen overvåkes hos alvorlig syke pasienter. Følgelig er det behov for å etablere en nasjonal standard for hjerneovervåking samt å arbeide systematisk med kompetanseheving.

Hjerneovervåking er et samlebegrep for den tette medisinske oppfølgingen i sykehus som kreves ved alvorlig sykdom i nervesystemet. I Norge rammes årlig over 20 ooo personer av akutt sykdom eller skade som krever hjerneovervåking (1). Hjerneovervåking er nødvendig i alle aldre og involverer alle nivåer av spesialisthelsetjenesten samt en rekke fag- og medisinske spesialiteter. Hjerneovervåkingsfeltet har gjennomgått en stor utvikling de senere årene (2). Nye behandlingsmetoder innen eksempelvis hjerneslag tydeliggjør behovet for mer avansert overvåking av hjernen på norske sykehus (므). Videre har utviklingen innen intensivmedisin, nevromonitorering, nevrosonologi, radiologi og klinisk nevrofysiologi bidratt til forbedret hjerneovervåking.

\section{Hva er hjerneovervåking?}


Hjerneovervåking defineres som klinisk nevrologisk, nevrofysiologisk, nevroradiologisk, ultralydbasert og invasiv monitorering av pasientens nervesystem. Hjerneovervåkingens formål er å så raskt som mulig påvise endret eller patologisk nevrologisk funksjon slik at korrekt behandling kan gis før irreversibel skade oppstår. Overvåkingen kan gjøres enten kontinuerlig eller intermitterende (tabell 1). Vitale organfunksjoner overvåkes parallelt, fordi nevrologisk funksjon er avhengig av adekvat respirasjon og sirkulasjon. Overvåkingen bør være kontinuerlig hos ustabile pasienter. Hos barn er sentralnervesystemet fortsatt i utvikling og følgelig spesielt sårbart. Tolkning av nevroradiologiske og nevrofysiologiske undersøkelser krever derfor spesialisert kunnskap om hjernefunksjon i ulike aldre. Nytteverdien av ulike monitoreringsverktøy for behandlingsvalg og prognose avhenger av grunnsykdommen.

\section{Tabell 1}

Metoder som inngår i hjerneovervåking.

\begin{tabular}{|c|c|}
\hline Form for overvåking & Beskrivelse \\
\hline Klinisk overvåking & $\begin{array}{l}\text { Vurdering av nevrologiske funksjoner: pupillereaksjoner, } \\
\text { svelgfunksjon, respirasjonsmuskulatur, autonome funksjoner, osv. } \\
\text { Overvåking av fysiologiske parametere: pulsfrekvens, hjerterytme, } \\
\text { blodtrykk, temperatur, respirasjonsfrekvens, oksygenmetning, } \\
\text { blodprøver med syre-base-status, glukose og elektrolytter, } \\
\text { væskebalanse. } \\
\text { Validerte kliniske skåringsverktøy, f.eks.: Glasgow Coma Scale, } \\
\text { FOUR (Full Outline of UnResponsiveness) Score, National Institute } \\
\text { of Health Stroke Scale (NIHSS). }\end{array}$ \\
\hline $\begin{array}{l}\text { Nevrofysiologisk } \\
\text { overvåking }\end{array}$ & $\begin{array}{l}\text { Kontinuerlig eller repetert EEG, fremkalte responsundersøkelser } \\
\text { (somatosensorisk fremkalte responser og auditivt fremkalte } \\
\text { responser). }\end{array}$ \\
\hline $\begin{array}{l}\text { Radiologiske } \\
\text { undersøkelser og } \\
\text { ultralyd }\end{array}$ & $\begin{array}{l}\text { CT caput, CT-angiografi, CT-perfusjon, MR caput, MR-angiografi, } \\
\text { MR-perfusjon og relevante protokoller, nevrosonologiske } \\
\text { undersøkelser (hemodynamikk, kollateralflow, perfusjon, } \\
\text { mikroemboluser, autoregulering/vasoreaktivitet, vasospasmer, } \\
\text { stenoser). }\end{array}$ \\
\hline $\begin{array}{l}\text { Invasive } \\
\text { overvåkingsmetoder }\end{array}$ & $\begin{array}{l}\text { Intrakranial trykk- og oksygenmåling, cerebrale } \\
\text { perfusjonsundersøkelser. }\end{array}$ \\
\hline
\end{tabular}

\section{Ulike behandlingsnivåer}

Hjerneovervåking foregår på ulike nivåer - intensivavdeling, intermediærenhet eller sengepost - avhengig av pasientens underliggende tilstand. Med basal hjerneovervåking menes klinisk nevrologisk undersøkelse, bruk av relevante skåringsverktøy og overvåking av vitale parametere (3) (tabell 1). Med avansert hjerneovervåking menes nevrofysiologiske undersøkelser, nevrosonologi, nevroradiologi og invasiv monitorering av hjernen.

Kontinuerlige eller gjentatte nevrofysiologiske og ultralydbaserte metoder gir sammen med klinisk vurdering verdifull sanntidsinformasjon om hjernens sirkulasjon og funksjon (4).

Det mangler imidlertid standardiserte nasjonale føringer og formelle opplæringskrav i hjerneovervåking. Kompetanse, tilgjengelighet og ferdigheter varierer mellom sykehusene, og spesielt elektroencefalografi (EEG) og nevrosonologi kan med fordel benyttes i større 
grad i intermediær- og intensivavdelingene. Dette understøttes av data fra Norsk intensivregisters årsrapport fra 2019 der kun 0,5\% av intensivpasientene hadde kontinuerlig EEG i løpet av oppholdet (5).

\section{Hvilke pasientgrupper trenger hjerneovervåking?}

De største pasientgruppene omfatter pasienter med akutt hjerneslag, hodetraumer, spinale traumer og multitraumer og alvorlig epilepsi. Andre aktuelle tilstander, som til sammen utgjør et stort antall, er ulike årsaker til nedsatt bevissthet, som forgiftning, hjertestans, nærdrukning, alvorlige metabolske forstyrrelser, infeksjoner og inflammatoriske tilstander, nevromuskulære sykdommer og kirurgi som krever peroperativ overvåking av nervesystemet. Mange pasienter med akutt nevrologisk sykdom har hjertesykdom eller respirasjonsvansker som påvirker hjernens funksjon og krever tettere overvåking.

\section{Hjerneovervåking av intensivpasienter}

I norske sykehus er det nærmere 20 ooo intensivopphold hvert år (5). Hos opptil 70 \% av intensivpasientene er hjernen affisert (므) som følge av primær hjernesykdom eller som ledd i annen organsykdom eller -svikt. Flertallet av nevrointensivpasientene er nevrokirurgiske pasienter. Imidlertid utgjør nevrologiske intensivpasienter en stadig større del av intensivpopulasjonen.

Hos alle nevrointensivpasienter er systematiske og repeterte kliniske nevrologiske undersøkelser med validerte skåringsverktøy hjørnesteiner i overvåkingen. De fleste nevrointensivpasienter har nedsatt bevissthet på grunn av sedasjon eller hjernesykdom, noe som nødvendiggjør avansert nevromonitorering, eksempelvis intrakranial trykkmåling og nevrosonologiske undersøkelser. European Society of Intensive Care Medicine anbefaler bruk av sedasjonsdybdemonitorering med prosessert EEG på alle sederte pasienter (7.). Kontinuerlig multikanal-EEG brukes ved epilepsi, men er også aktuelt ved andre tilstander som intrakraniale blødninger, infeksjoner og hodeskader. Fremkalte responser og EEG er viktige prognostiske verktøy ved anoksisk hjerneskade. Transkranial ultralyd brukes ved ulike problemstillinger innen hjerneslag og ved økt intrakranialt trykk inkludert dødsdiagnostikk. Nevrosonologisk måling av nervus opticus-skjedediameter er sannsynligvis den beste ikke-invasive metoden for påvisning av økt intrakranialt trykk (ㅁ).

\section{"Til tross for at hjernen er målorganet ved anestesi, finnes det ingen standard for hjerneovervåking under narkose»}

Erkjennelsen av at hjernefunksjonen påvirkes og kan forverres ved overdosering av sedativer har bidratt til økt bruk av sedasjonsdybdemonitorering. Det er ønskelig at sedasjonen skal være så lett som mulig, også for å øke verdien av klinisk nevrologisk unders $ø$ kelse. Pasienter med nevrologisk eller nevrokirurgisk sykdom trenger sedasjon og demping av autonom aktivering i kritiske perioder med risiko for hjerneødem og iskemi, men langvarig og dyp sedasjon øker risikoen for delirium, redusert kognitiv funksjon og tap av muskelmasse (9.). Enkelte pasienter utvikler såkalt critical illness-polynevropati og myopati. Nevrofysiologiske undersøkelser som EEG, elektromyografi og nevrografi benyttes for å påvise alvorlig cerebral skade eller critical illness-polynevropati og -myopati. Med mobilt CT-apparat vil man kunne utføre CT, CT-angiografi og CT-perfusjon på intensivenhet uten å transportere pasienten til radiologisk avdeling. Dette vil kunne være et betydelig bidrag innen avansert hjerneovervåking.

\section{Hjerneovervåking under anestesi og kirurgiske prosedyrer}


Til tross for at hjernen er målorganet ved anestesi, finnes det ingen standard for hjerneovervåking under narkose. Klinisk vurdering av narkosedybde kan suppleres av EEGbasert monitorering. Prosessert EEG, som bispektral indeks (BIS) eller EEG-spektrogram, kan brukes for måling av narkosedybde ved generell anestesi (10). Overvåking av nevrologisk funksjon under store inngrep reduserer risikoen for skader. Eksempler på slik nevromonitorering er perioperativ kontinuerlig måling av fremkalte responser i motoriske og sensoriske baner. Inngrep i hjerte, aortabue og store precerebrale og cerebrale arterier er høyrisikoinngrep med tanke på nevrologiske komplikasjoner. Cerebral oksymetri som overvåker oksygentilførsel til hjernen, og nevrosonologisk måling av hjernesirkulasjon kan påvise og tidvis forhindre skader i hjernen ved slike inngrep (1ㅡ).

\section{Hjerneovervåking av hjerneslagpasienter}

Pasienter med hjerneslag nevnes spesielt som den største gruppen pasienter med akutt hjernesykdom der optimal overvåking bidrar til å begrense hjerneskade (모). Det har lenge vært kjent at god overvåking og regulering av basale parametere ved hjerneslag har betydning for senere funksjon hos den enkelte pasient (13). Overvåkingen av hjerneslagpasienter bør derfor skje i en slagenhet med spesialopplært fagpersonell (14). Tettere overvåking av bevissthet, nevrologiske symptomer og vitale funksjoner er avgjørende for å hindre unødvendig nevrontap, funksjonstap og større senskader hos minst hver fjerde akutte slagpasient (15). Slik overvåking bør gjennomføres i egne overvåkingssengeplasser med kontinuerlig oppfølging (므). I den kritiske overvåkingsfasen er det også verdifullt å vurdere cerebral blodgjennomstrømning med transkranial ultralyd (17.). Ved intrakraniale blødninger, inkludert subaraknoidalblødning, er hjernens blodforsyning kritisk påvirket, og følgeskader er vanlig (묘). For å oppdage eller følge utviklingen av karspasmer i hjerneblodkar bør transkranial ultralyd, cerebral CT-angiografi og cerebrale perfusjonsundersøkelser være tilgjengelige. Måling av intrakranialt trykk, vevsoksygenering og temperatur er sentralt hos slike pasienter.

Selv om flere universitetssykehus og noen større sykehus har bygd opp hjerneovervåking på intermediærenhet i slagenhetene, er det fremdeles stor geografisk variasjon i tilbudet til slagpasienter (19). Det er behov for standardisert overvåking av pasienter med akutt

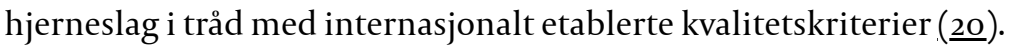

\section{Behov for nasjonale retningslinjer}

Hjerneovervåking er multidisiplinært. Samarbeid på tvers av spesialiteter er en forutsetning for god behandling av akutt alvorlig hjernesykdom. Ved mange sykehus, inkludert universitetssykehusene, er kompetansen i nevrointensivmedisin per i dag personavhengig. Formaliserte, multidisiplinære nevrointensivteam vil øke kvaliteten på tjenesten og gjøre den mer robust. Det er behov for nasjonale retningslinjer og standarder for hjerneovervåking for å sikre en systematisk tilnærming og et likeverdig tilbud mellom sykehusene. Etablering av hjerneovervåking i slagenheter på alle landets sykehus i henhold

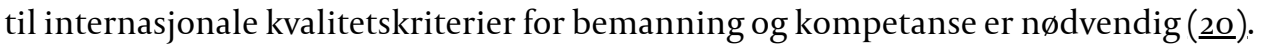

EEG-overvåking er et sentralt verktøy for å overvåke hjernefunksjon. Døgnkontinuerlig tilgjengelighet på nevrofysiologisk kompetanse er nødvendig. Mange sykehus har fortsatt ikke personell med tilstrekkelig nevrofysiologisk kompetanse (1ㅡ). Utvikling av telemedisinske løsninger mellom sykehus og regioner kan bedre tilbudet.

\section{Må få større plass i utdanningen}


Vi mener at hjerneovervåking og nevrointensivmedisin bør få en større plass både i grunnutdanningen av leger og sykepleiere og i relevante spesialistutdanninger. Det bør etableres nasjonale videreutdanningskurs i nevrointensivmedisin eller tilrettelegges for deltakelse i skandinaviske program. Leger og sykepleiere som behandler alvorlig hjernesykdom, bør ha gjennomgått opplæring, inkludert sertifisering i validerte kliniske skåringsverktøy, og ha god teoretisk og praktisk kunnskap om hjerneovervåking og ulike behandlinger. Dette inngår ikke i tilstrekkelig grad i dagens bachelor-og spesialistutdanning.

Store fremskritt i en rekke fagfelt gjør at vi i dag kan behandle mange pasienter med svært alvorlige sykdommer og skader i både nervesystemet og øvrige organer. Tilbudet på norske sykehus i dag for overvåking av hjerne og nervesystem i de mest kritiske sykdomsfasene står ikke i forhold til verken behovet eller den medisinske utviklingen, til tross for at det finnes god dokumentasjon på at hjerneovervåking på sykehus redder nevrologisk funksjon og kan være avgjørende for både overlevelse og prognose.

\section{LITTERATUR}

1. Statusrapport for hjernehelse. Rapport IS-2588. Oslo: Helsedirektoratet, 2017.

https://www.helsedirektoratet.no/rapporter/statusrapport-

hjernehelse/Statusrapport\%2ohjernehelse.pdf/_attachment/inline/7d59bc61-6239-4do6-9aa6987ee4454850:288b5aof6oe635edcfc3a872158af2cbd37eb6dc/Statusrapport\%2ohjernehelse.pdf Lest 20.9.2021.

2. Kramer AH, Couillard P. Neurocritical care: A growing international collaborative. Neurocrit Care 2020; 32: 80-3. [PubMed][CrossRef]

3. Kondziella D, Bender A, Diserens Ket al. European Academy of Neurology guideline on the diagnosis of coma and other disorders of consciousness. Eur J Neurol 2020; 27: 741-56. [PubMed] [CrossRef]

4. Bermeo-Ovalle A. Bringing EEG back to the future: Use of cEEG in neurocritical care. Epilepsy Curr 2019; 19: 243-5. [PubMed][CrossRef]

5. Buanes EL, Kvåle R, Barratt-Due A. Norsk intensivregister. Årsrapport for 2019 med plan for forbedringstiltak. Bergen: Helse Bergen, 2019.

https://www.kvalitetsregistre.no/sites/default/files/37_arsrapport2019_norsk_intensivregister.pdf Lest 20.9.2021.

6. Bolton CF, Young GB. Neurological complications in critically ill patients. Neurology and General Medicine 2008: 981-97.

7. Claassen J, Taccone FS, Horn P et al. Recommendations on the use of EEG monitoring in critically ill patients: consensus statement from the neurointensive care section of the ESICM. Intensive Care Med 2013; 39: 1337-51. [PubMed][CrossRef]

8. Evensen KB, Eide PK. Measuring intracranial pressure by invasive, less invasive or non-invasive means: limitations and avenues for improvement. Fluids Barriers CNS 2020; 17:34. [PubMed] [CrossRef]

9. Ely EW, Shintani A, Truman B et al. Delirium as a predictor of mortality in mechanically ventilated patients in the intensive care unit. JAMA 2004; 291: 1753-62. [PubMed][CrossRef]

10. Chan MTV, Hedrick TL, Egan TD et al. American Society for Enhanced Recovery and Perioperative Quality Initiative Joint Consensus Statement on the Role of Neuromonitoring in Perioperative Outcomes: Electroencephalography. Anesth Analg 2020; 130: 1278-91. [PubMed][CrossRef]

11. Soh S, Shim JK, Song JW et al. Preoperative transcranial Doppler and cerebral oximetry as predictors of delirium following valvular heart surgery: a case-control study. J Clin Monit Comput 2020; 34: 715-23. [PubMed][CrossRef]

12. Ciccone A, Celani MG, Chiaramonte R et al. Continuous versus intermittent physiological monitoring for acute stroke. Cochrane Database Syst Rev 2013; 31: CDoo8444. [PubMed][CrossRef]

13. Gorelick PB, Qureshi S, Farooq MU. Management of blood pressure in stroke. Int J Cardiol Hypertens 2019; 3: 100021. [PubMed][CrossRef]

14. Stroke Unit Trialists' Collaboration. Organised inpatient (stroke unit) care for stroke. Cochrane Database Syst Rev 2013; 2013: CDoo0197. [PubMed] 
15. Faigle R, Marsh EB, Llinas RH et al. ICAT: a simple score predicting critical care needs after thrombolysis in stroke patients. Crit Care 2016; 20: 26. [PubMed][CrossRef]

16. White PM, Bhalla A, Dinsmore J et al. Standards for providing safe acute ischaemic stroke thrombectomy services (September 2015). Clin Radiol 2017; 72: 175.e1-9. [PubMed][CrossRef]

17. Kargiotis O, Psychogios K, Safouris A et al. Transcranial doppler monitoring of acute reperfusion therapies in acute ischemic stroke patients with underlying large vessel occlusions. J Neurosonol Neuroimag 2020; 12:10-25. [CrossRef]

18. Gruenbaum SE, Bilotta F. Postoperative ICU management of patients after subarachnoid hemorrhage. Curr Opin Anaesthesiol 2014; 27: 489-93. [PubMed][CrossRef]

19. Norsk hjerneslagregister, årsrapport 2019. Med plan for forbedringstiltak. Trondheim: St. Olavs hospital, 2020. https://stolav.no/fag-og-forskning/medisinske-kvalitetsregistre/norskhjerneslagregister Lest 20.9.2021.

20. Waje-Andreassen U, Nabavi DG, Engelter ST et al. European Stroke Organisation certification of stroke units and stroke centres. Eur Stroke J 2018; 3: 220-6. [PubMed][CrossRef]

21. Norsk forening for klinisk nevrofysiologi. Strategisk plan for KNF 2011. https://www.legeforeningen.no/foreningsledd/fagmed/norsk-forening-for-klinisknevrofysiologi/Faglige-ressurser/metoder-prosedyrer/strategisk-plan-for-knf-2011/ Lest 20.9.2021.

Publisert: 20. oktober 2021. Tidsskr Nor Legeforen. DOI: 10.4045/tidsskr.21.0412

Mottatt 13.5.2021, første revisjon innsendt 5.9.2021, godkjent 20.9.2021.

(C) Tidsskrift for Den norske legeforening 2023. Lastet ned fra tidsskriftet.no 26. april 2023. 